\title{
Thermoeconomic Analysis of Alessandria District: A Case Study for an Engineering Thermodynamic Indicator for Sustainability
}

\author{
Giulia Grisolia*, Umberto Lucia \\ Dipartimento Energia “Galileo Ferraris”, Politecnico di Torino, Corso, Duca degli Abruzzi 24, Torino 10129, Italy \\ Corresponding Author Email: giulia.grisolia@polito.it
}

https://doi.org/10.18280/ti-ijes.652-402

Received: 25 March 2021

Accepted: 19 May 2021

\section{Keywords:}

thermoeconomy, sustainability, indicators, human development index

\begin{abstract}
Gross Domestic Product is usually the reference indicator to quantify the socio-economic consequences of the national policies due to its link to the increase of the nation well-being. But it is used to evaluate the total monetary valuation of the productive systems, without any relation to the technological level or the environmental impact. These GDP characteristics represent the difficulties for sustainability to be realised. So, in this report, we wish to suggest a new indicator for the analysis of sustainability, with particular regards to the human wellbeing. This new indicator is based on the exergy analysis of dissipation and irreversibility. Moreover, energy is one of the fundamental drivers of the development, and of the economic growth. Last, in industrialized countries, the management of $\mathrm{CO}_{2}$ emissions represents one of the present imperative issues. Indeed, improving the energy efficiency and its rational use is one of the key economic strategies in order to achieve the target of moving towards a more sustainable development. The suggested indicator allows us to consider all these requests, for the progress towards a sustainable development, resulting a very interesting thermoeconomic quantity to be used by decision-makers. The Alessandria district is analysed as a case study.
\end{abstract}

\section{INTRODUCTION}

Nowadays, big efforts are required to the scientific community in order to find technical solutions in cutting the carbon dioxide emissions, which represent the main contributor to the global warming. But, reducing the causes of global warming due to human behaviors is directly linked to the concepts of sustainability and sustainable development. In this context, an useful approach that has been introduced in engineering is the operation management, which is focused on [1]:

- The management of the resources needed to produce/manufacture a product or provide a service [2];

- $\quad$ The designing phase, considering also all the operation chain, with the aim of improving all the systems required to obtain primary products and services [3].

Another relevant aspect of the efficient and effective resources and systems management is related to the wide numbers of workers which are involved on them, which is linked with at least two -society and economy- of the three pillars of sustainability. Moreover, an approach based on the sustainable development has been introduced within natural and environmental sciences, in order to provide information and to assist decision-makers and business stakeholders in their choices, which final aim must be meet the needs of the actual without compromising those of the future generations [4].

A key role in controlling all the stages of the value creation and of the production chain is played by business activities, which are directly linked with the use of resources and related to the effects on the environment [1]. On the other hand, business activities can represent one of the powerful tools to achieve sustainability [5], impacting on most choices at a global level.

So, recently, there has been an increase in the research activity related to sustainability, with a great variety of interests in all fields, including the engineering one. Here, we focus our interest on the main areas of sustainability:

- Environment;

- Economy;

- Society.

These topics must be linked with the technological improvement, which puts the spotlight on:

- The use of cleaner technologies;

- The variation on employment and resources management;

- The growth of new markets.

Since the last decades of 1800, the development of mathematical approaches to economic activities has been introduced, and these approaches were based on natural-lawlike principles, with the result of achieving objective functions for households and firms, and also conditions of equilibrium for decisions on the economy. During the 1900, the socioeconomical decisions have been always driven by social and political needs. However, the technological innovations of the production system due to the revolutions have been driven by an economic growth and social changes. The increasing knowledge in physical and health sciences, have had a key role in the analysis of the present social interconnections among economy, technical improvements and ecological consequences. Moreover, new policies of intervention were needed in order to offset the achievement of optimal conditions, to reach the foreseen economic equilibrium. To 
achieve this result, the main tools adopted have been the following: variations in prices of goods and services, introduction of taxes, variations of the forms of markets themselves. However, when the thermodynamic approach has been introduced on economy, the equilibrium theory has been opposed to an approach based on open systems, at steady state conditions. Thus, the behavior of the economy must be analogous to the living systems one. This implies having constraints, which are related to the laws of nature and to the presence of finite resources on the Earth system. This new approach has led the economists interest towards the environmental and ecological issues, recognizing the significance of the resource and the wastes into the economic theories.

All the anthropic activities must be considered within the constraints of the system on which humans operate, which are only the laws of nature. So, any consideration on the anthropic activities must be related to them.

What can link all these (apparently) different subjects one another?

Energy represents the fundamental source for any activity. However, energy is a topic of research of thermodynamics, so a new approach is required in order to link economy to thermodynamics.

Indicators are the main tool adopted to monitor and to assess the achievement of benchmarks related to the performances of a region/country/process. They are useful to assist the decision-makers and stakeholders with their decision processes. Therefore, indicators are both quantitative and qualitative measurements [6] of a certain change, providing information about the variation caused by a certain stimulus in time.

The requirement to dispose of information and data availability, regarding the conditions of all countries and regions, is set in Chapter 40 of Agenda 21 [7]. This hascontributed to introduce and develop indicators of sustainability, in order to assist the decision-makers towards an integration of the environmental issues into the human wellbeing. In this context, since the sustainable development has been introduced - despite the debate on its definition $[8,9]$ huge efforts have been made in order to monitor the progress towards a more sustainable management of resources and of policy decisions. Thus, a wide number of indicators and indexes of sustainable development have been developed during the last decades, in order to monitor and to assess the performance of sustainable policies and they have been introduced in the socio-economic and ecological analyses [10].

The aim of this paper is just to propose a new indicator (the Thermodynamic Human Development Index), useful to evaluate human activities, in relation to their impact on the human well-being, on the environment, and on the social economy, in order to introduce a thermoeconomic approach based on optimization, and useful to reduce the environmental consequences of human activities and to improve the human well-being, too.

\section{THE THERMODYNAMIC HUMAN DEVELOPMENT INDEX}

Nowadays, we have come to a crossroad in the human history, with related consequences on the Earth. Complex dynamics due to the growth of the poverty distribution, and of the increase of the ecological, environmental and socio- economic downgrading, are causing a severe socio-economic system of despair from which it is very difficult to brakeout.

Sustainable consumption of resources, production and energy policies are the keys for a sustainable development [11] Moreover, a growing request in bio-based industrial raw materials requires a reorganization of the chains of the energy and industrial sectors. This is based on new technological choices, with the need of sustainable measurements of their impacts on the environment, society and economy.

Engineering and technological improvements can represent new opportunities for the renewal of the world, but new indicators for the decision-makers are required. In this context, social and economic requirements must be taken into account, too. Sustainable policies require new indicators, able to link economics, technologies and social well-being, together.

In 1990, the Human Development Index has been introduced by the United Nations Development Programme (UNDP) $[12,13]$, as a multidimensional index to measure the development of a country from a socio-economic viewpoint, with the aim to switch the focus from a pure economic development to a more human-centred one $[13,14]$.

However, nowadays we must consider also the consequences of the anthropic activities on the environment and, the indicators used to assess human well-being cannot neglect these effects.

In this section, an irreversible thermodynamic approach is developed in order to introduce the Thermodynamics Human Development Index, an indicator based on the thermodynamic optimisation approach, and linked to socio-economic and ecological evaluation.

The Human Development Index (HDI) is a composite index, which is focused on three key dimensions of human development: the possibility to lead a long and healthy life (measured by the life expectancy at birth), the possibility to achieve a good level of knowledge (measured by mean years of schooling and by the expected years of schooling), and the possibility to achieve a decent standard of living (measured by gross national income per capita).

Two different key roles - played by the HDI - have been identified by Stanton [15]:

- a tool to understand human development in relation to human well-being;

- $\quad$ an alternative indicator to Gross Domestic Product per capita (GDPpc) in order to measure and compare levels of development of countries.

So, the Human Development Index considers the developing level of a country, related to education, health and salary conditions. It is defined as $[16,17]$ :

$$
H D I=\sqrt[3]{L E I \cdot E I \cdot I I}
$$

where $[16,18]$ :

$$
L E I=\frac{L E-2}{65}
$$

being LEI the Life Expectancy Index, and LE the Life expectancy at birth, and where $[15,19]$ :

$$
E I=\frac{M Y S I+E Y S I}{2}
$$

being EI the Education Index, with MYSI the Mean Years of 
Schooling Index and EYSI the Expected Years of Schooling Index,

$$
I I=\frac{\ln \left(\frac{G N I_{p c}}{100}\right)}{\ln 750}
$$

being II the Normalised Income Index, where GNIpc is the gross national income per capita, at purchasing power parity [12]. The use of the logarithmic function allows us to have a diminishing results for higher incomes. Moreover, the value of 75,000 US\$ per capita represents a threshold above which no gains in the human development and well-being are considered [18]. The United Nations have considered the Gross National Income instead of the Gross Domestic Product to better capture the income of the residents [20,21].

However, the Human Development Index HDI doesn't take into account the technological and ecological level reached by the considered society.

Consequently, we introduce a new indicator, based on the Gouy Stodola theorem [22], useful in engineering optimisation, the Thermodynamic Human Development Index, that we define as [23]:

$$
T H D I=\sqrt[3]{\frac{L E I \cdot E I}{I_{T}}}
$$

where [24]:

$$
I_{T}=\frac{T_{0} m_{\mathrm{CO}_{2}} s_{g}}{W \cdot G N I_{p c}}=0.01 \cdot \frac{T_{0} m_{\mathrm{CO}_{2}} s_{g}}{W} \cdot 750^{-I I}
$$

being $T_{0}$ the environmental temperature, $m_{\mathrm{CO}_{2}}$ is the mass of carbon dioxide emissions due to the anthropic activities in the atmosphere, sg the specific entropy generation, and $W$ the useful work obtained.

The result obtained is the Thermodynamic Human Development Index, THDI, which is a thermoeconomic indicator, which improves the usual Human Development Index, HDI, by taking into account also the technical and ecological level of the considered society, by introducing the carbon dioxide emissions and the specific entropy generation (sg) quantities, related to the irreversibility of the processes. As it occurs for the HDI, a higher value of THDI implies a higher human-wellbeing, considering also the negative interactions of the population with the environment in terms of carbon dioxide emissions.

\section{AN APPLICATION: THE ALESSANDRIA DISTRICT}

Here, we apply the new indicator, THDI, in the district of Alessandria, Piedmont Region (Italy), in order to show the improvements in relation to the usual HDI. We base our considerations in relation to the available data, related to the year 2004 [25], considering only the flows of exergy associated to energy resources, neglecting the flows of products and services derived from them. Alessandria is one of the eight districts of the Piedmont region, Italy: it covers a surface of $3,560 \mathrm{~km}^{2}$ (about $14 \%$ of the total surface of
Piedmont), with a population of around 440,613 people (about $10 \%$ of the total population of Piedmont), including 190 municipalities, among which its administrative centre: the municipality of Alessandria. In particular, we analyse the municipality of Alessandria, which covers $204 \mathrm{~km}^{2}$ with a population of 93,922 people. We consider the exergy flows related only to the city management, which are useful to obtain information from the energy management of the city administration. These exergy flows (inflowing and outflowing from the municipality), related to 2004, can be divided by sectors and by primary source (Electricity and Fuel).

The exergy inflows considered are the following [25]:

- From the tertiary sector, which involves mainly the consumption of building heating, of water systems and electrical appliances. The exergy inflow has been evaluated as follows: 712 TJ from Electricity (85\% due to low temperature heat) and $559 \mathrm{TJ}$ from Fuels, with a total amount of $1,271 \mathrm{TJ}$;

- From the residential sector, where the consumption is mainly due to residential lightening, heating, etc. The exergy inflow has been evaluated as follows: $309 \mathrm{TJ}$ from Electricity and 2,825 TJ from Fuels, with a total amount of 3,134 TJ;

- $\quad$ From the public transport, where the main input is the fuel, which is converted into mechanical power. Its exergy inflow has been evaluated as follows: $14 \mathrm{TJ}$ from Electricity and $29 \mathrm{TJ}$ from Fuels, with a total amount of $43 \mathrm{TJ}$;

- $\quad$ From the private transport, where the exergy inflow has been evaluated respectively as follows: negligible $(0 \mathrm{TJ})$ from Electricity and 2,230 TJ from Fuels, with a total amount of 2,230 TJ;

The exergy outflows considered are the following:

- $\quad$ From the tertiary sector uses: 289 TJ (low temperature heat $182 \mathrm{TJ}$, other uses $107 \mathrm{TJ}$ ) from Electricity and 148 TJ from Fuels, with a total amount of $437 \mathrm{TJ}$;

- $\quad$ From the residential sector uses: $125 \mathrm{TJ}$ (low temperature heat 79 TJ, other uses $46 \mathrm{TJ}$ ) from Electricity, and $992 \mathrm{TJ}$ from Fuels, with a total amount of $1,117 \mathrm{TJ}$;

- $\quad$ From the public transport: 0 TJ from Electricity, and 10 TJ from Fuels, with a total amount of $10 \mathrm{TJ}$;

- $\quad$ From the private transport: 0 TJ from Electricity, and 652 TJ from Fuels, with a total amount of $652 \mathrm{TJ}$;

Thus, the total exergy inflow and outflow from the municipality amounts respectively to $6,678 \mathrm{TJ}$ and to $2,216 \mathrm{TJ}$, with a relative exergy loss of 4,462 TJ.

Now, it is possible to present a possible scenario by considering two different choices at a local administration level: the introduction of a municipal district heating, and the improvement of the public transport system. In particular we assume that:

- The introduction of district heating for the overall Municipality would decrease:

i. The exergy inflow for tertiary sector of electricity uses to $107 \mathrm{TJ}$ for the Electricity and to $0 \mathrm{TJ}$ for the Fuels;

ii. By $90 \%$ the amount of inflowing and outflowing exergy from fuels in the residential sector;

- The improvement of the municipal public transportation would:

iii. Increase the exergy inflow in public transport to $100 \mathrm{TJ}$, with a related exergy outflow of $34 \mathrm{TJ}$;

iv. Decrease the exergy inflow due to private transport to $1,400 \mathrm{TJ}$, with a related exergy outflow of $409 \mathrm{TJ}$. 
Which means varying the exergy losses and the related carbon dioxide emissions. Indeed, the exergy losses are proportional to the entropy generation and to the environmental temperature.

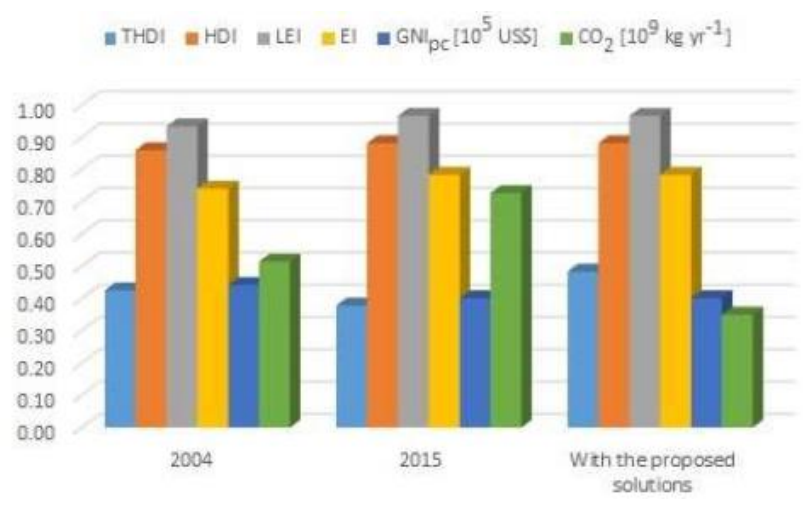

Figure 1. Thermodynamic Human Development Index (THDI) of Alessandria District, Human Development Index (HDI), Life Expectancy Index (LEI), Education Index (EI), Gross National Income per capita (GNIpc), Carbon dioxide emissions $\left(\mathrm{CO}_{2}\right)$ in 2004, 2015 and in a scenario, which corresponds to the proposed policy administration solutions, in order to reduce the carbon dioxide emissions

In Figure 1, in order to show the information represented by our indicator, in relation to the well-being and to the environmental carbon dioxide emissions, the comparison between two years (2004 and 2015), has been represented among the following indicators: the Thermodynamic Human Development Index (THDI) of Alessandria District, the Human Development Index (HDI), the Life Expectancy Index (LEI), the Education Index (EI), the Gross National Income per capita (GNIpc), and the Carbon dioxide emissions $\left(\mathrm{CO}_{2}\right)$.

It is possible to highlight that:

- $\quad$ The life expectancy index (LEI) and the accessibility to education (EI) have increased by $4 \%$ and $6 \%$ respectively in 2015, in relation to 2004;

- The Gross National Income per capita has decreased by $9 \%$ in 2015 , in relation to 2004 ;

- $\quad$ The carbon dioxide emissions of the entire municipality have increased by $41 \%$ in 2015 , in relation to 2004 ;

- $\quad$ The Human Development Index (HDI) has increased by $3 \%$ in 2015 , in relation to 2004 ;

- $\quad$ The Thermodynamic Human Development Index (THDI) has decreased by $11 \%$ in 2015 , in relation to 2004 . Indeed, it takes into account the human well-being related to education, life expectancy at birth and decent standards of living, but also the worsened global environmental conditions due to the carbon dioxide emissions;

In order to show the results of the same quantities, obtained from the hypothesized scenario, we present a third series of data, where we consider the two above different policy choices for the municipality of Alessandria: the introduction of a municipal heating network, and the improvement of the public transport network, that imply a reduction on carbon dioxide emissions. For this scenario, it is possible to highlight that:

- All the indicators that are useful to calculate the HDI (Life Expectancy Index, Education Index and Income Index) remain unchanged. Therefore, the Human Development Index (HDI) remains constant with the introduction of the environmental solutions. It is possible to point out that HDI does not take into account the ecological and technological improvements introduced in the scenario;

- $\quad$ The Thermodynamic Human Development Index (THDI) has increased by $27 \%$ if we consider the real values of 2015 and those of the hypothesized situation. This is due to the improvements introduced in the latter case in reducing the carbon dioxide emissions. The result is in accordance with Eq. (6), because it takes into account of the positive effects into the environmental conditions.

\section{CONCLUSIONS}

Today, we have arrived to a crossroad in the human history, but also for the environment on which we rely on. Actually, a complex dynamics regarding the growth of the poverty distribution, and also the increase of the ecological, environmental and socio-economic degradation, are continuously generating difficult socio-economic despairs, from which it is very difficult to outbreak [26]. On the other hand, the progresses on healthcare, the access to basic services to a large number of people, the always more widespread awareness on environmental issues, bring to new scenarios towards which we have to move on.

From the middle of the XIX century, the rate of exploitation of natural resources and the subsequent environmental degradation has quicken, as a result of the development of industry, technology and global market, with some nonpositive consequences on our planet, such as [26, 27]:

- The hole in the ozone layer, that implies the loss of the protection of the Earth in relation to dangerous Sun radiations, which is able to filter out the ultraviolet radiation;

- The loss of about $65 \%$ of previously lands useful for agriculture;

- The desertification by $15 \%$ of the land surface, transformed into arid surfaces;

- The emission of chemicals into the environment;

- The biodiversity loss;

- The global mean temperature increase: according to NOAA's 2020 Annual Climate Report [28] it has increased at an average rate of $0.08^{\circ} \mathrm{C}$ per decade since 1880 and, this average rate of increase has more than doubled since $1981\left(0.18^{\circ} \mathrm{C}\right)$. During the period 19902018, the global carbon dioxide emissions - the primary driver of climate change - have increased by $65 \%$ [29].

Moreover, another consideration that burdens the economic and financial system is the gap among the earnings: about the $20 \%$ of people earn more than 200 times compared to the remaining $80 \%$ [26]. A consequence of this issue are unavoidable people fluxes from poorer countries to the richest ones.

All these considerations are useful to point out that a paradigm shift is required in approaching sustainable development and sustainability. Furthermore, concerns about global warming and human-well being are progressively putting the spotlight on all the aspects of sustainable development [1].

Here, we have developed a new indicator, which introduces technological and ecological quantification into the United Nations indicator, Human Development Index. To do so, we have introduced the entropy generation due to carbon dioxide emissions, into the HDI, with the result of taking into account of the technological and ecological level of the 
Country/Region considered, in addition to the socio-economic quantification of the United Nations HDI. Indeed, the entropy generation is related to the Gouy-Stodola theorem, which takes into account the exergy lost due to irreversibility. This quantity is able to assign a quantitative evaluation to the technological level; indeed, the grater is the technological level, the lower is the value of the entropy generation, because of the optimization of the system considered. Moreover, the new indicator takes also into account of the environmental temperature, fundamental aspect of the specificity of any country, but also of the global warming.

In order to show the information that can be obtained by the Thermodynamic Human Development Index, we have analyzed it for the Alessandria district, in order to show its different behavior when compared to the Human Development Index, highlighting how our indicator can be interesting, because it contains also information on sustainability because it considers the actions towards sustainability. We wish to highlight that social and economic development are required in order to provide an effective sustainability for all people. Nevertheless, these forms of development cannot be decoupled from their effects on the environment. So, the THDI changes in relation both to the human well-being and to the environmental conditions.

\section{REFERENCES}

[1] Corbett, L.M. (2009). Sustainable operations management: A typological approach. Journal of Industrial Engineering and Management (JIEM), 2(1): 10-30. https://doi.org/10.3926/jiem.v2n1.p10-30

[2] Constable, C.J., New, C.C. (1976). Operations Management: A Systems Approach Through Text and Cases. Chichester: Wiley.

[3] Jacobs, F.R., Chase, R.B., Aquilano, N.J. (2004). Operations Management for Competitive Advantage. Boston: Mc-Graw Hill, 64: 70.

[4] Brundtland, G.H. (1987). Our Common Future Oxford University Press. New York.

[5] Tang, K., Yeoh, R. (2007). Cut carbon, Grow Profits: Business Strategies for Managing Climate Change and Sustainability. Libri Pub Limited.

[6] Joint Research Centre-European Commission. (2008). Handbook on constructing composite indicators: methodology and user guide. OECD publishing. Available: https://www.oecd.org/sdd/42495745.pdf.

[7] United Nations General Assembly. Report of the United Nations Conference on Environment and Development Agenda 21. Report. UN: New York, NY, 1992.

[8] Rogers, P.P., Jalal, K.F., Boyd, J.A. (2012). An Introduction to Sustainable Development. Earthscan.

[9] Wu, J., Wu, T. (2012). Sustainability indicators and indices: An overview. Handbook of Sustainability Management,

65-86. https://doi.org/10.1142/9789814354820_0004

[10] Hák, T. (2007). Sustainability Indicators: A Scientific Assessment. Island Press.

[11] Akenji, L., Bengtsson, M. (2014). Making sustainable consumption and production the core of sustainable development goals. Sustainability, 6(2): 513-529. https://doi.org/10.3390/su6020513

[12] Desai, M. (1991). Human development: concepts and measurement. European Economic Review, 35(2-3): 350-357.
[13] Sagar, A.D., Najam, A. (1998). The human development index: A critical review. Ecological Economics, 25(3): 249-264. https://doi.org/10.1016/S0921-8009(97)001687

[14] Hickel, J. (2020). The sustainable development index: Measuring the ecological efficiency of human development in the anthropocene. Ecological Economics, 167:

106331. https://doi.org/10.1016/j.ecolecon.2019.05.011

[15] Stanton, E.A. (2007). The human development index: A history. PERI Working Papers, 85.

[16] United Nations Development Programme. (2013). Human Development Report 2015: Concept and Measurement of Human Development. New York, NY. Available: http://www.hdr.undp.org/en/reports/global/hdr1990

[17] Human Development Report Office. (2015). Training Material for Producing National Human Development Reports. Occasional paper, UNDP, New York, NY.

[18] Javaid, A., Akbar, A., Nawaz, S. (2018). A review on human development index. PJHSSR, 6: 357-369. https://doi.org/10.52131/pjhss.2018.0603.0052

[19] MPI. Calculating the Human Development IndicesGraphical Presentation. Human Development.

[20] Dervis, K., Klugman, J. (2011). Measuring human progress: the contribution of the Human Development Index and related indices. Revue d'économie Politique, 121(1): 73-92. https://doi.org/10.3917/redp.211.0073

[21] Pinar, M., Stengos, T., Topaloglou, N. (2017). Testing for the implicit weights of the dimensions of the human development index using stochastic dominance. Economics Letters, 161: 38-42. https://doi.org/10.1016/j.405 econlet.2017.09.023

[22] Bejan, A. (2006). Advanced Engineering Thermodynamics, Hoboken, NJ: J. Wiley, 49-146.

[23] Lucia, U., Grisolia, G. (2021). The gouy-stodola theorem-from irreversibility to sustainability - the thermodynamic human development index. Sustainability, 13(7): 3995. https://doi.org/10.3390/su13073995

[24] Lucia, U., Grisolia, G. (2021). Irreversible thermodynamics and bioeconomy: Toward a humanoriented sustainability. Frontiers in Physics, 9: 154. https://doi.org/10.3389/fphy.2021.659342

[25] Lucia, U., Grisolia, G. (2017). Unavailability percentage as energy planning and economic choice parameter. Renewable and Sustainable Energy Reviews, 75: 197204. https://doi.org/10.1016/j.rser.2016.10.064

[26] Hathaway, M., Boff, L. (2009). The Tao of Liberation. Exploring the Ecology of Transformation. Maryknoll, NY: Orbis Book, 1-55.

[27] Brown, L.R., Renner, M., Halweiln, B. (2007). Vital Signs 2006-7: Trends That are Shaping Our Future. Worldwatch Ins., Washington, D.C.

[28] NOAA National Centers for Environmental Information. (2020). State of the climate: Global climate report for annual 2019.

[29] Ritchie, H., Roser, M. (2020). $\mathrm{CO}_{2}$ and greenhouse gas emissions. Our world in data.

\section{NOMENCLATURE}

$\mathrm{CO}_{2} \quad$ Carbon dioxide emissions, $\mathrm{kg} \mathrm{yr}^{-1}$ 


$\begin{array}{ll}E I & \text { Education Index } \\ E Y S I & \text { Expected Years of Schooling Index } \\ \text { GDP } & \text { Gross Domestic Product, US\$ } \\ G N I & \text { Gross National Income, US\$ at PPP } \\ I I & \text { Income Index } \\ I & \text { Indicator } \\ H D I & \text { Human Development Index } \\ \text { LE } & \text { Life Expectancy at birth } \\ \text { LEI } & \text { Life Expectancy Index } \\ M Y S I & \text { Mean Years of Schooling Index } \\ T H D I & \text { Thermodynamic Human Development } \\ & \text { Index }\end{array}$

Mass, kg

$s$

\section{Subscripts}

$\begin{array}{ll}T & \text { Thermodynamic } \\ g & \text { Generation, due to irreversibility } \\ p c & \text { Per capita } \\ 0 & \text { Environment conditions }\end{array}$

